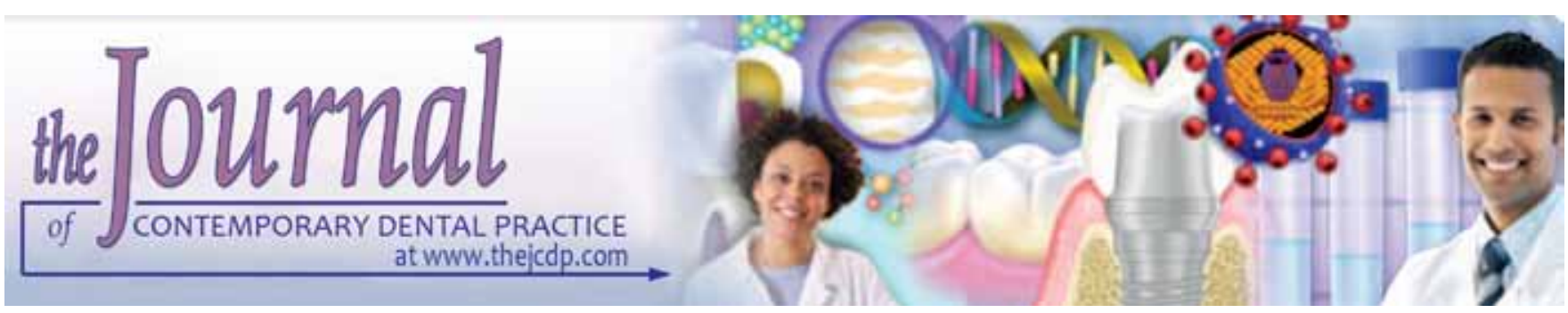

\title{
Color Stability and Surface Roughness of Composite submitted to Different Types and Periods of Finishing/ Polishing: Physical Properties of Composites
}

${ }^{1}$ Renata Costa de Morais, ${ }^{2}$ Lucas da Fonseca Roberti Garcia

${ }^{3}$ Diogo Rodrigues Cruvinel, ${ }^{4}$ Fernanda de Carvalho Panzeri Pires-de-Souza

\begin{abstract}
Aim: The aim of this study was to evaluate the influence of accelerated artificial aging (AAA) on color stability $(\triangle E)$ and surface roughness of composite submitted to different systems and periods of finishing/polishing.

Materials and methods: A Teflon matrix was used to fabricate 60 specimens that were separated into four groups, according to the finishing/polishing system: G1: no polishing; G2: abrasive papers; G3: rubber polishing disks; and G4: G2 + G3 Polishing was performed at three different time intervals $(n=6)$ : immediately (Im), 24 hours (24 hours) and 7 days ( 7 day) after specimen fabrication. Initial color and surface roughness readouts were taken. Afterwards, specimens were submitted to AAA (480 hours) and new readouts were taken.
\end{abstract}

Results: Results demonstrated that G2 (7 day) presented lower $\Delta \mathrm{E}$, statistically different from $\mathrm{G} 1$ and $\mathrm{G} 4$ (7 days) (two-way analysis of variance (ANOVA), Bonferroni, $p<0.05$ ).

Conclusion: Regarding roughness, there was no difference among groups and periods. Polishing performed with abrasive papers, 7 days after performing the restoration, promoted less color alteration.

Clinical significance: Most of composite restorations are replaced within a period shorter than 5 years due to esthetic failure, and correct finishing and polishing procedures are fundamental to avoid these problems.

Keywords: Aging, Color perception, Composites, Dental polishing.

\footnotetext{
${ }^{1-4}$ Department of Dental Materials and Prosthodontics, Ribeirão Preto School of Dentistry, University of São Paulo, Ribeirão Preto, São Paulo, Brazil

Corresponding Author: Fernanda de Carvalho Panzeri Pires-de-Souza, Associate Professor, Department of Dental Materials and Prosthodontics, Ribeirão Preto School of Dentistry University of São Paulo, Ribeirão Preto, São Paulo Brazil, Phone: +55 (016) 3602-3973, e-mail: ferpanzeri@usp.br
}

How to cite this article: de Morais RC, da Fonseca Roberti Garcia L, Cruvinel DR, Pires-de-Souza FCP. Color Stability and Surface Roughness of Composite submitted to Different Types and Periods of Finishing/Polishing: Physical Properties of Composites. J Contemp Dent Pract 2015;16(7):565-570.

Source of support: São Paulo Research Foundation (Process 2012/08193-0) and CAPES (Process 88881.030486/ 2013-01).

\section{Conflict of interest: None}

\section{INTRODUCTION}

Growing esthetic demands have led to increasingly wider use of dental composites by dentists, making them one of the most popular materials at present. ${ }^{1}$ This use is mainly due to the improvements in both the mechanical and esthetic properties of these materials. ${ }^{1,2}$ Nevertheless, around $50 \%$ of composite restorations are replaced within a period shorter than 5 years, the main reason being color alteration that occurs with the course of time..$^{3,4}$

Color alteration of composites can basicallybeexplained as a result of three factors: (1) external discoloration, due to bacterial plaque accumulation, dietary habits and smoking; (2) alterations on the surface and subsurface of the composite, allowing penetration and reaction of solutions that promote staining (adsorption); and (3) intrinsic discoloration, due to physicochemical reactions in the deep portions of the restoration. ${ }^{5}$

Intrinsic discoloration of the composite is mainly related to the hydrophilic nature of its resin matrix, which regulates the degree of water sorption; in other words, the more hydrophilic the matrix, the more water sorption will occur, promoting greater degradation of the polymeric network. ${ }^{6,7}$ In addition, other chemical additives present in composite formulations, particularly those that do not undergo reaction, such as initiators, inhibitors, 
accelerators and ultraviolet filters, also promote color alteration with the course of time, due to their natural degradation process. $^{8}$

Composites are traditionally classified according to the size of their load particles. ${ }^{9,10}$ Therefore, load particle size and distribution also play an important role in this context; because the larger the particle size, greater is the light dispersion within the material, making it more opaque. ${ }^{11,12}$

In the same way as type, size and volume of load particles vary among different composite formulations found in the market. These factors interfere in the different procedures of finishing and polishing of the material. ${ }^{13}$ The smaller the load particle of a composite, the easier it will be to polish, giving it greater surface smoothness and less presence of microfailures, making it difficult for staining solutions to penetrate; and consequently, there will be less color alteration. ${ }^{14}$

Adequate finishing and polishing are clinical procedures of fundamental importance to these properties in dental composites. ${ }^{15}$ However, an inherent problem found in these procedures is the fact that the resin matrix and load particles have different hardnesses, and do not wear in the same proportion, resulting in irregularities on the material surface and greater susceptibility to color alterations after polishing. ${ }^{16}$

At present, manufacturers offer a variety of systems for performing finishing and polishing on composites, which the authors classify in four large groups: covered with abrasives (finishing disks); cutting devices (carbide burs and polishing stones); microdiamond burs and abrasives made of rubber; and abrasives with loss of particles (polishing powders and pastes). ${ }^{13}$

Generally, the polishing capacity of a material with regard to the system used is tested in vitro on flat test specimens, with the aid of dental handpieces and predetermined rotation speed of the polishing disk. ${ }^{17}$ It is worth pointing out, however, that as composite restorations can be polished immediately or after they have been made, it is necessary to evaluate whether this procedure performed at different time intervals is capable of interfering in the optical properties of the material or not. ${ }^{17}$

Thus, the aim of this study was to evaluate the influence of accelerated artificial aging (AAA) on color stability and surface roughness of composite submitted to different systems and periods of finishing/polishing. The null hypothesis tested was that there would be no difference in the levels of alteration to which the material was submitted, irrespective of the system and period of finishing and polishing.

\section{MATERIALS AND METHODS}

A teflon matrix (8 $\mathrm{mm}$ in diameter and $2 \mathrm{~mm}$ thickness) was used to fabricate 60 test specimens from a hybrid composite (Filtek Z250, 3M ESPE, Sumaré, SP, Brazil), composed of bisphenol A-glycidyl dimethacrylate (Bis-GMA), urethane dimethacrylate (UDMA), bisphenol A ethoxylate dimethacrylate (Bis-EMA), inorganic silica/ zirconia load particles of 0.01 to $3.5 \mu \mathrm{m}$ in $60 \%$ (by vol).

The composite was inserted in the matrix in $1 \mathrm{~mm}$ increments, and the last increment was pressed with a glass slide to allow excess material to flow out. After insertion in the matrix, each increment was light activated using a LED type appliance (FLASHlite 1401, Discus Dental, Culver City, CA, USA) for 20 seconds, in accordance with the manufacturer's recommendations.

After this, the test specimens were randomly separated into four groups, according to the finishing/polishing system used: Group 1: no polishing (control); Group 2: polishing with abrasive papers (Norton, São Paulo, SP, Brazil: 320, 600 and 1200 grains); Group 3: rubber polishing disks (EVE Ecocomp, EVE, Pforzheim, Germanymedium and fine grains); and Group 4: abrasive papers + rubber polishing disks. These procedures were performed at three different time intervals $(\mathrm{n}=6)$ : immediately, 24 hours and 7 days after test specimen fabrication. As Group 1 (control) was not submitted to any type of polishing, only 6 test specimens were used.

\section{Color Stability}

After obtaining the test specimens, initial color readouts were taken (Spectrophotometer Easyshade, VITA Zahnfabrik, Bad Säckingen, Germany), according to the CIE $\mathrm{L}^{*} \mathrm{a}^{*} \mathrm{~b}^{*}$ system (Comission Internationale de I'Éclairage).

Next, the specimens were submitted to AAA (accelerated aging system for nonmetallic materials C-UV, Comexim Matérias Primas Ltda, São Paulo, SP, Brazil) for 480 hours, which corresponds to 1 year of clinical use. ${ }^{18}$ The fixed working program was 4 hours of exposure to UV-B at $50^{\circ} \mathrm{C}$ and 4 hours of condensation at $50^{\circ} \mathrm{C}$.

After AAA, new color readout was performed and color stability $(\triangle \mathrm{E})$ was determined by the difference between the coordinates obtained before and after the aging process of the specimens, by the following formula: ${ }^{19}$

$\Delta \mathrm{E}=(\Delta \mathrm{L})^{2}+(\Delta \mathrm{a})^{2}+(\Delta \mathrm{b})^{2}$

where:

$\Delta \mathrm{E}=$ color alteration

$\Delta \mathrm{L}=\mathrm{L}^{*} \mathrm{~F}-\mathrm{L}^{*} \mathrm{I}$

$\Delta \mathrm{a}=\mathrm{a}^{*} \mathrm{~F}-\mathrm{a}^{*} \mathrm{I}$

$\Delta \mathrm{b}=\mathrm{b}^{*} \mathrm{~F}-\mathrm{b}^{*} \mathrm{I}$

Values of $\Delta \mathrm{E}<3.3$ were considered clinically unacceptable. $^{20}$ 


\section{Surface Roughness}

To verify surface roughness of the test specimens, the roughness meter Mitutoyo SJ-201P was used (Mitutoyo, Tokyo, Japan; cut-off $0.25 \mathrm{~mm}$; speed $0.1 \mathrm{~mm} / \mathrm{s}$ ).

In the same way as for the color readouts, roughness readouts were taken before and after AAA to determine the variation in surface roughness of the test specimens. After obtaining the data of the different tests, these were submitted to statistical analysis for two factors-type and period of polishing (two-way analysis of varianceANOVA, Bonferroni, $\mathrm{p}<0.05)$.

\section{RESULTS}

\section{Color Stability}

The results obtained in the color stability analysis may be seen in Table 1 . When analyzing the results, it was observed that all the groups, irrespective of the finishing/ polishing period, presented color alteration above the clinically acceptable limit. Group 2 presented the least variation in $\Delta \mathrm{E}$ at 7 days, with statistically significant difference in comparison with G1 and G4 in the same period $(\mathrm{p}<0.05)$. Whereas, with regard to the different periods, G2 (7 days) and G4 (24 hours) showed the lowest variation, with statistically significant difference in comparison with the periods immediate and 7 days $(\mathrm{p}<0.05)$.

\section{Surface Roughness}

The results of the surface roughness analysis may be seen in Table 2.

With regard to the different types of finishing/polishing, G4 presented the highest surface roughness ' $\mathrm{Ra}^{\prime}$

Table 1: Mean values and standard deviation of color stability analysis $(\Delta \mathrm{E})$ of the different groups

\begin{tabular}{lllll}
\hline & \multicolumn{4}{c}{ Types of polishing } \\
\cline { 2 - 5 } Time & $\mathrm{G} 1$ & $\mathrm{G} 2$ & $\mathrm{G} 3$ & $\mathrm{G} 4$ \\
\hline Immediate & 10.81 & $12.28(1.07)^{\mathrm{aA}}$ & 11.47 & $12.02(0.49)^{\mathrm{aA}}$ \\
& $(1.52)^{\mathrm{aA}}$ & & $(0.40)^{\mathrm{aA}}$ & \\
24 hours & & $12.27(1.11)^{\mathrm{aA}}$ & 10.84 & $9.20(0.32)^{\mathrm{aB}}$ \\
& & & $(1.02)^{\mathrm{aAB}}$ & \\
7 days & & $8.78(0.69)^{\mathrm{bB}}$ & 9.94 & $11.55(0.44)^{\mathrm{aA}}$ \\
& & & $(0.76)^{\mathrm{abB}}$ & \\
\hline
\end{tabular}

Different capital letters in columns and lower case letters in the lines represent statistically significant difference (two-way ANOVA, Bonferroni test: $p<0.05$ )

Table 2: Mean values and standard deviation of surface roughness alteration $\left(R_{a}\right)$ of the different groups

\begin{tabular}{lllll}
\hline & \multicolumn{4}{c}{ Types of polishing } \\
\cline { 2 - 5 } Time & G1 & G2 & G3 & G4 \\
\hline Immediate & & $0.07(0.04)$ & $0.30(0.10)$ & $0.33(0.10)$ \\
24 hours & $0.48(0.39)$ & $0.18(0.18)$ & $0.38(0.11)$ & $0.54(0.22)$ \\
7 days & & $0.11(0.03)$ & $0.17(0.28)$ & $1.50(0.09)$ \\
\hline
\end{tabular}

There was no statistically significant difference (two-way ANOVA, Bonferroni, $p<0.05)$ for any of the studied groups $(p>0.05)$ value, however, without statistically significant difference as compared to the other groups ( $p>0.05)$. The same was observed in case of periods of finishing/polishing, which there was no statistically significant difference among the groups $(\mathrm{p}>0.05)$.

\section{DISCUSSION}

In the present study, the effect of AAA on color stability and surface roughness of a dental composite submitted to different systems and periods of finishing/polishing was evaluated. Based on the results obtained, it may be affirmed that the tested hypothesis was partially accepted, since there was a difference in the levels of color alteration as a result of the systems and periods of finishing/polishing studied, however, there was no significant alteration in surface roughness.

The efficiency of the finishing and polishing procedures of composites has developed constantly, and has become an important factor in the maintenance of esthetic properties and longevity of restorations. ${ }^{21}$ Sequential polishing techniques have been routinely used in dental practice to obtain restorations with a smooth surface free of interferences, thus reducing the rates of staining and consequently, color alteration of these materials. ${ }^{21}$

The staining capacity of composites is related to their conversion degree and chemical characteristics. ${ }^{22}$ Composites with a high conversion degree rate have advantageous characteristics in comparison to others, such as less susceptibility to resin matrix degradation by the substances present in the oral environment, and adequate optical properties. ${ }^{7}$

Insufficient monomer conversion and the presence of unconverted double carbon bonds make the material more susceptible to reactions of degradation, resulting in reduced color stability, due to lixiviation of by products, such as methacrylic acid, formaldehyde and specific molecules of methacrylate. ${ }^{7,8}$ In addition, unreacted monomers act as resin matrix plasticizers, reducing the mechanical properties of the material, particularly hardness. ${ }^{7,23}$ The plasticization rate of a polymer is directly related to the adsorption rate of the solvent, which initiates immediately after placing the restorative material in function in the oral cavity; and attains its maximum degree in approximately 2 months when the polymeric network is completely saturated. ${ }^{7}$

The complex polymerization mechanism of Bis-GMAbased composites results in conversion degree rate range from 45 to $85 \%{ }^{24}$ Soares et al demonstrated a negative correlation between composites with a conversion degree between 55 and $65 \%$ and the depth of wear by abrasion of these materials, in other words, the lower the degree of conversion, the greater the wear capacity of a 
restoration. ${ }^{24}$ It is known that composites formulated with the mixture of Bis-GMA and UDMA, such as Z250, have a $20 \%$ lower conversion degree than those formulated with the mixture of other monomers. However, there is no consensus to a minimum value for the conversion degree so that a restoration will present a satisfactory clinical performance. ${ }^{25}$

Clinical and laboratory evaluations have pointed out a relationship between conversion degree and various properties of composites, however, the effect of monomer conversion on these properties may be masked by other factors, such as load particle size, shape and distribution. ${ }^{6,7}$

The color alteration observed in this study may be explained by the variation between load particle size present in Z250 (0.01-3.5 $\mu \mathrm{m})$ and by their volume $(60 \%)$. Larger load particles present a different degree of degradation than that of smaller particles. ${ }^{26}$ Considering that color perception is directly related to the reflection of incident light on the composite, greater the variety in particle size, greater is the scattering of light beams and lower is the color stability of the material. ${ }^{26}$

Dental composites with a concentration of load particles of over $50 \%$, such as Z250, have a lower conversion degree, and consequently, more remaining double bonds and fewer bonds formed, resulting in extensive degradation. $^{7}$

It is known that AAA produces color alterations above the clinically acceptable limits because of surface and subsurface degradation that occurs in the composite. ${ }^{23}$ The results of the present study also demonstrate this. However, it was observed that when polishing is performed with abrasive papers after 7 days, this alteration may diminish in comparison with the other studied periods.

According to Shintani et $\mathrm{al}^{27}$ composites light activated against a glass slide, as was done in the present study, tend to present a surface rich in organic matrix, with a lower quantity of load particles, more chemically unstable and capable of absorbing water with greater facility, increasing their staining capacity. When polishing is performed with abrasive papers, a greater degree of wear may occur on this surface that is richer in organic matrix before AAA, which could mean less color alteration. The same does not occur when a rubber polishing disk is used, unless it is used in conjunction with abrasive paper.

Time appears to be an important factor in composite polishing. When it occurs 7 days after light activation, one has a composite with a higher conversion degree, in spite of $90 \%$ of the composite polymerization occurring at the time of light activation. ${ }^{24}$ This conversion, which continues, allows a higher level of cross links between the chains, enhancing the properties of the material. ${ }^{7,24}$ When this surface is polished, the entire unstable layer is removed from the surface, whose subsurface has a higher conversion degree than that of the samples polished earlier, and thus there is less staining by AAA (Table 2).

Various studies have related load particle size and shape to the polishing capacity and surface roughness of composites. ${ }^{28,29}$ However, Berger et $\mathrm{al}^{30}$ observed that in spite of roughness and staining being intimately associated $^{31}$, the technique and the materials used for polishing restorations have a greater influence on these properties than the size and distribution of the load particles present in composites. The same was reported by Ghinea et al, who demonstrated that finishing/polishing is a determinant factor for the maintenance of surface roughness values of hybrid, microhybrid and microparticulate composites. $^{31}$

The increase in roughness, associated with the increase in the number of porosities present on composite surfaces promotes loss of mass of the material, and consequently, greater water sorption, resulting in color alteration. ${ }^{32}$ Silva et al observed that restorations polished 24 hours and 7 days after they were fabricated presented less alteration in surface roughness than restorations polished immediately after being fabricated. ${ }^{33}$ However, in the present study, there was no significant alteration in the roughness values, irrespective of the type and period of finishing/polishing used. These differences in the results between surface roughness and color stability, according to Giacomelli et al, may be attributed to both the intrinsic characteristics of the composites and the different techniques and materials used for polishing, which present different effects on one and the same surface. ${ }^{34}$

It is also worth pointing out that there is a critical value with respect to alterations in surface roughness. According to Bollen et al, an increase of $\geq 0.2 \mu \mathrm{m}$ in surface roughness promotes greater biofilm retention, leading to an increase in recurrent caries. ${ }^{35}$ An increase of $0.3 \mu \mathrm{m}$ may be detected by the patients lips and tongue, causing discomfort. Among the groups evaluated in the present study, it was observed that only G2 (in all periods) and G3 (7 days) did not present Ra values above the critical levels for surface roughness. Once again, it was verified that polishing with abrasive papers allowed more adequate surfaces to be obtained after polishing.

\section{CONCLUSION}

Based on the results obtained, it could be concluded that the different types and periods of finishing/polishing interfere in the color stability of composites, however, they do not alter the surface roughness. Polishing performed 
with abrasive papers after 7 days promoted less color alteration. However, irrespective of the type and period of finishing/polishing used, all groups presented color alteration above of the clinically acceptable limit.

\section{CLINICAL SIGNIFICANCE}

Most of composite restorations are replaced within a period shorter than 5 years due to esthetic failure, and correct finishing and polishing procedures are fundamental to avoid these problems.

\section{REFERENCES}

1. Marghalani HY. Effect of filler particles on surface roughness of experimental composite series. J Appl Oral Sci 2010;18(1):59-67.

2. Gaengler P,Hoyer I, Montag R, Gaebler P. Micromorphological evaluation of posterior composite restorations-a 10-year report. J Oral Rehabil 2004;3(10)1:991-1000.

3. Deligeorgi V, Mjör IA, Wilson NH. An overview of reasons for the placement and replacement of restorations. Prim Dent Care 2001;8(1):5-11.

4. Mjör IA, Moorhead JE, Dahl JE. Reasons for replacement of restorations in permanent teeth in general dental practice. Int Dent J 2000;50(6):361-366.

5. Soares LE, Cesar IC, Santos CG, De Cardoso AL, Liporoni PC, Munin E, Martin AA. Influence of coffee on reflectance and chemistry of resin composite protected by surface sealant. Am J Dent 2007;20(5):299-304.

6. Bagheri R, Burrow MF, Tyas M. Influence of food-simulating solutions and surface finish on susceptibility to staining of aesthetic restorative materials. J Dent 2005;33(5):389-398.

7. Ferracane JL. Hygroscopic and hydrolytic effects in dental polymer networks. Dent Mater 2006;22(3):211-222.

8. Santerre JP, Shajii L, Leung BW. Relation of dental composite formulations to their degradation and the release of hydrolyzed polymeric-resin-derived products. Crit Rev Oral Biol Med 2001;12(2):136-151.

9. Korkmaz Y, Ozel E, Attar N, Aksoy G. The influence of onestep polishing systems on the surface roughness and microhardness of nanocomposites. Oper Dent 2008;3(1)3:44-50.

10. Ruttermann S, Wandrey C, Raab WHM, Janda R. Novel nanoparticles as fillers for an experimental resin-based restorative material. Acta Biomater 2008;4(6):1846-1853.

11. Rodrigues SA Jr, Scherrer SS, Ferracane JL, Della Bona A. Microstructural characterization and fracture behavior of a microhybrid and a nanofill composite. Dent Mater 2008;24(9):1281-1288.

12. Kim KH. Ong JL. Okuno O. The effect of filler loading and morphology on the mechanical properties of contemporary composites. J Prosthet Dent 2002;87(6):642-649.

13. Choi MS, Lee YK, Lim BS, Rhee SH, Yang HC. Changes in surface characteristics of dental resin composites after polishing. Journal of Materials Science. J Mater Sci Mater Med 2005;16(4):347-353.

14. Guler AU, Kurt S, Kulunk T. Effects of various finishing procedures on the staining of provisional restorative materials. J Prosthet Dent 2005;93(5):453-458.
15. Jefferies SR, Barkmeier WW, Gwinnett AJ. Three composite finishing systems: a multisite in vitro evaluation. J Esthet Dent 1992;4(6):181-185.

16. Chung $\mathrm{KH}$. Effects of finishing and polishing procedures on the surface texture of resin composites. Dent Mater 1994;10:325-330.

17. Heintze SD, Forjanic M, Rousson V. Surface roughness and gloss of dental materials as a function of force and polishing time in vitro. Dent Mater 2006;22(2):146-165.

18. ASTM G154-00A. Standard practice for operating fluorescent light apparatus for UV exposure of nonmetallic materials. Annual Book of ASTM Standards. Pennsylvania: ASTM International West Conshohocken, PA; 2006. p. 646-654.

19. Pires-de-Souza FCP C, Casemiro LA, Garcia Lda F, Cruvinel DR. Color stability of dental ceramics submitted to artificial accelerated aging after repeated firings. J Prosthet Dent 2009;101(1):13-18.

20. Ruyter IE, Nilner K, Moller B. Color stability of dental composite resin materials for crown and bridge veneers. Dent Mater 1987;3(5):246-251.

21. Atabek D, Sillelioglu H, Olmez A. The efficiency of a new polishing material: nanotechnology liquid polish. Oper Dent 2010;35(3):362-369.

22. Micali B. Basting RT. Effectiveness of composite resin polymerization using light-emitting diodes (LEDs) or halogenbased light-curing units. Braz Oral Res 2004;18(3):266-270.

23. Schulze KA, Marshall SJ, Gansky SA, Marshall GW. Color stability and hardness in dental composites after accelerated aging. Dent Mater 2003;19(7):612-619.

24. Soares LES, Liporoni PCS, Martin AA. The effect of softstart polymerization by second generation LEDs on the degree of conversion of resin composite. Oper Dent 2007;32(2):160-165.

25. Shimomura H. Photochemical studies on composite resins cured by visible light. Dent Mater J 1987;6(1):9-27.

26. Pires-de-Souza FCP, Garcia Lda F, Hamida HM, Casemiro LA. Color stability of composites subjected to accelerated aging after curing using either a halogen or light emitting diode source. Braz Dent J 2007;18(2):119-123.

27. Shintani H, Satou N, Yukihiro A, Satou J, Yamane I, Kouzai T, Andou T, Kai M, Hayashihara H, Inoue T. Water sorption, solubility and staining properties of microfilled resins polished by various methods. Dent Mater J 1985;4(1):54-62.

28. Reis AF, Giannini M, Lovadino JR, Ambrosano GM. Effects of various finishing systems on the surface roughness and staining susceptibility of packable composite resins. Dent Mater 2003;19(1):12-18.

29. Hosoya Y, Shiraishi T, Puppin-Rontani RM, Powers JM. Effects of acidulated phosphate fluoride gel application on surface roughness, gloss and colour of different type resin composites. J Dent 2011;39(10):700-706.

30. Berger SB, Palialol AR, Cavalli V, Giannini M. Surface roughness and staining susceptibility of composite resins after finishing and polishing. J Esthet Restor Dent 2011;23(1):34-43.

31. Ghinea R, Ugarte-Alvan L, Yebra A, Pecho OE, Paravina RD, Perez Mdel M. Influence of surface roughness on the color of dental-resin composites. JZhejiang Univ Sci B2011;12(7):552-562.

32. Zanin FR, Garcia Lda F, Casemiro LA, Pires-de-souza Fde C. Effect of artificial accelerated aging on color stability and surface roughness of indirect composites. Eur J Prosthodont Restor Dent 2008;16(1):10-14. 
33. Da Silva FMJ, Da Rocha MD, Travassos CA, Fernandes BVV Jr, Rodrigues RJ. Effect of different finishing times on surface roughness and maintenance of polish in nanoparticle and microhybrid composite resins. Eur J Esthet Dent 2010;5(3): 288-298.

34. Giacomelli L, Derchi G, Frustaci A, Bruno O, Covani U, Barone A, De Santis D, Chiappelli F. Surface roughness of commercial composites after different polishing protocols: an analysis with atomic force microscopy. Open Dent J 2010;4:191-194.

35. Bollen CM, Lambrechts P, Quirynen M. Comparison of surface roughness of oral hard materials to the threshold surface roughness for bacterial plaque retention: a review of the literature. Dent Mater 1997;13(4):258-269. 